\title{
La Amazonía ecuatoriana representada por los medios de comunicación desde el discurso orientalista
}

The Ecuadorian Rainforest Presented by the Media through the Orientalist Discourse

Nori Melissa Castro Parra de Ciencias Sociales (FLACSO). (Sede Ecuador) nmcastrof@@lacso.eduec

\section{Castro Parra, N.M., (2019)}

a Amazonía ecuatoriana representada por los medios evistiscurso orientalista aDResearch ESIC. NN 20 Vol 20

Segundo semestre, Jllo diciembre 2019. Págs. 80 a 103 https://doi.org/10.7263/adresic-020-06
Clasificación JEL:

Palabras clave:

Amazonía,

análisis crítico del

discurso,

representaciones mediáticas

ABSTRACT

JEL Classification

L82, N56

Key words:

The Amazon

Rainforest,

critical discourse

analysis,

orientalism,

media representations
Objetivo: Analizar las representaciones mediáticas de la Amazonía que el diario El Comercio rasgos del discurso orientalista.

Diseño/metodología: Se utiliza el Análisis Crítico del Discurso como propuesta metodológica, pues ella ayuda a develar las desigualdades sociales que se producen en los discursos. Dentro de esta línea de estudios se toma el análisis estructural del texto como herramienta metodológica que permite deconstruir los discursos dominantes que se reproducen en la sociedad a través de los medios de comunicación.

Resultados: Realizado el análisis se encontró que la población, la cultura y la geografía de la región han sido representadas desde categorías que reproducen otredad, causando asimetría social dentro del pais. Esta desigualdad, que ha sido legitimada por el discurso mediático, puede observase en el retraso y la marginación que sufre esta zona hasta la actualidad.

Limitaciones/implicaciones: Una de las limitaciones del estudio es que el interés mediático sobre la región amazónica se centra en momentos coyunturales relacionados con la explotación de recursos, lo cual impide que las seis décadas hayan sido estudiadas de forma continua. En vista de esta situación lo que se ha hecho es marcar un hito histórico por cada uno de los seis últimos decenios y tomarlos como referentes para desarrollar la investigación.

Originalidad/contribución: La Amazonía ha sido un territorio históricamente marginado y su población ha sido desatendida por los diferentes gobiernos que han administrado el país, a pesar de ser la región que más ha aportado a la economía de Ecuador con sus riquezas naturales. Esta situación de injusticia social no se ha habla estudiado antes en el discurso mediático, que es el principal discurso legitimador de inequidades hoy en día, es por esta razón que se decidio realizar el presente estudio.

Purpose: To analyse the media presentations of the Ecuadorian Rainforest that the newspaper EI Comercio has been elaborating during the last six decades in its journalistic articles in order to discover features of the orientalist discourse.

Design/methodology: The Critical Discourse Analysis is used as a methodological tool since it helps to reveal social inequalities that occur in discourses. Within this line of study, the structural analysis of the text is taken as a methodological tool that allows deconstructing dominant discourses echoed in society through the media.

Findings: The analysis found that the population, culture and geography of the region have been represented by categories that show otherness and cause social asymmetry within the country. This inequality, which has been legitimized by the media discourse, can be observed in the backwardness and marginalization that this region has suffered until now.

Research limitations/implications: One of the limitations of the study is that the media interest in the Amazon region is directed on events related to the exploitation of resources, which means that the last six decades have not been studied continuously. In view of this situation, we wish to mark a historical milestone for each of the last six decades and take them as references for further research.

Originality/value: The Amazon Rainforest has been a historically marginalized territory and its population has been neglected by different governments that have administered the country in spite of being the region that has contributed the most to Ecuador's economy with its natural wealth. This situation of social injustice has not been studied before in the media discourse, which is the main discourse legitimizing inequalities today. For this reason, the present study was developed. 


\section{Introducción}

Desde la época de la colonia la región amazónica

fue un territorio que llamó la atención de los conquistadores por considerarla un espacio lleno de recursos naturales susceptibles de ser explotados para el beneficio de los centros de poder. Sin embargo, a pesar de los múltiples viajes que realizaron los extranjeros a la zona, jamás pudieron dominarla porque ellos no estaban acostumbrados habitar en estos territorios. De esta manera, se fueron armando relatos sobre las expediciones al lugar; como muestra de ello está el libro «Viaje de exploración al Oriente ecuatoriano, 1887-1888» de François Pierre. En esta obra el autor describe a la Amazonía como «aquellas regiones tenidas por impracticables y [los] pueblos renombrados por su ferocidad» (Pierre, 1999, p. 13). El texto de Pierre constituye un ejemplo del discurso que se manejó en la época colonial y que describió a los conquistadores como valientes caballeros que exploraron rincones desconocidos y a la región como una zona hostil.

Para el tiempo en el que surgió esta obra no resulta nada extraño el lenguaje que se utilizó para describir a la Amazonía, pues así se construyó el discurso colonial que creó un imaginario negativo de la región en el resto del país. No obstante, desde la época de la colonia y la expedición de Pierre ya ha pasado más de un siglo, por lo cual resulta interesante conocer cuál es el discurso que se ha manejado sobre esta zona en los últimos años. En este sentido, se toman las representaciones mediáticas como una muestra del discurso dominante que circula entre la población ecuatoriana. Así pues, como sostiene Stuart Hall (2010) los medios de comunicación tienen la capacidad de producir y reproducir ideas en la sociedad. Con esto no se pretende decir que los medios tengan un poder inagotable, pero sí que tienen la facultad de difundir ideas en la colectividad, y dicha facul- tad es aún mayor cuando los ciudadanos carecen de experiencias de primera mano sobre el tema que se les está informando (Lippmann, 2003; Charaudeau, 2003). Este es justamente el caso que plantea el presente estudio, pues sostiene que los ecuatorianos que no conocen la región tienen como único referente de ella lo que han leído, escuchado o visto en los mass media

De esta manera, vale señalar que se ha escogido a un medio escrito pues lo que se procura realizar es un análisis histórico de las últimas seis décadas, y en dicho periodo ni la radio ni la televisión gozaban mucha popularidad en el país. Asimismo, hay que decir que se opta por El Comercio porque es un diario de alcance nacional que lleva en circulación 112 años y, porque siempre ha estado vinculado con las esferas del poder político y económico de la nación.

Así pues, lo que se propone esta investigación es descubrir cómo el diario El Comercio ha representado a la Amazonía en sus discursos en los últimos tiempos para conocer si a través de estas representaciones se ha construido a la región como el Oriente ecuatoriano desde el discurso orientalista, puesto que esta zona todavía resulta desconocida para muchos ecuatorianos y el referente de lo que saben sobre ella lo obtienen de los medios de comunicación.

\section{Las representaciones de la realidad}

\section{n los medios de comunicación}

Al ser las representaciones mediáticas el objeto de estudio es necesario hacer un abordaje teórico sobre ellas. Inicialmente es necesario conocer: ¿qué es una representación? Para responder a esta interrogante hay que recurrir a la propuesta de Stuart Hall que sostiene que la representación es la «producción de sentido de los conceptos en nuestras mentes mediante el lenguaje. Es el vínculo entre los conceptos y el lenguaje el que nos capacita para referirnos al mundo» (Hall, 1997, p. 15). De acuerdo con lo que plantea el autor la representación es un proceso que permite conecta las representaciones mentales con la realidad para darle un sentido, un significado a dicha realidad. Además, el autor propone que este proceso se da mediante el uso del lenguaje, pues este sería el elemento que posibilitaría la elaboración de representaciones. En este sentido, el autor afirma: «La relación entre las 'cosas', conceptos y signos está en el corazón de la producción de sentido dentro de un lenguaje. El proceso que vincula estos tres elementos y los convierte en un conjunto es lo que denominamos 'representaciones' (Hall, 1997, p. 17)

Asimismo, hay que decir que las representaciones alcanzan un carácter social cuando se vuelven el referente de una comunidad determinada, de modo que guían el comportamiento de los miembros y su relacionamiento con el en torno (Moscovici, 1979, p. 33). Vale menciona que las representaciones se pueden compartir escala social gracias a la existencia del lenguaje, es por ello que este elemento se vuelve un parte constitutiva de ellas. Pero, ¿cómo es que una representación llega a ser aceptada y compartida en una sociedad? Según Alejandro Raite existen instituciones sociales con la capacidad para lograr que una determinada representación sea aceptada colectivamente, como los medios de comunicación (Raiter, 2002, p. 15). Es este rol privilegiado de los medios el que interesa a presente estudio pues gracias a dicho papel pueden construir representaciones sociales sobre la Amazonía, que en última instancia influyen en la percepción que tienen los ecuatorianos acerca de la región

Teniendo en cuenta esta información es necesario enfocarse específicamente en las representaciones mediáticas. Éstas son entendidas como las representaciones sociales que construyen los medios de comunicación sobre la realidad. Como ya se mencionó anteriormente, los medios gozan de prestigio y credibilidad por cuanto son considerados una institución social. De modo que las representaciones que los medios elaboran sobre la realidad calan en las audiencias y se convierten en el referente que posee la población sobre lo que acontece en la sociedad.

Acerca de esto Walter Lippmann sostiene que los mass media representan a la realidad de manera parcial, creando «pseudo entornos» que facilitan a las personas conocer realidades a las que no pueden acceder a través de la experiencia. El autor afirma que «Este es el caso del ciudadano medio, ya que al no conocer directamente los dramáticos acontecimientos nacionales e internacionales acerca de los que lee, se limita a acumular experiencia de segunda mano vistas a través de las interpretaciones de terceros» (Lippmann, 2003, p. 17) Es decir, los ciudadanos al no estar en contacto directo con ciertas realidades pueden acceder a su conocimiento gracias a las construcciones mediáticas que elaboran los periodistas. Así pues, cuando se trata de realidades lejanas lo único que le queda a la población es acumular el conocimiento de la realidad que le brindan los medios de comunicación.

De igual forma, Patrick Charaudeau sostiene que el poder de los medios de comunicación para influir sobre el conocimiento de la realidad que tienen los ciudadanos es mayor cuando ellos poseen un escaso o nulo conocimiento sobre la realidad que está siendo representada a través de la información (Charaudeau, 2003, p. 14) Esto significa que las representaciones mediáticas que ha construido El Comercio son especialmente importantes para el segmento de la población ecuatoriana que no conoce la Amazonía, pues el único referente de lo que sabe sobre este te- 
rritorio, su gente y su cultura lo ha obtenido de la información que le brindan los medios de comunicación.

Asimismo, Patrick Champagne sostiene que as representaciones mediáticas, aunque están muy lejos de mostrar la realidad, son asimiladas por los ciudadanos de manera efectiva porque se elaboran sobre la base de prejuicios (Champagne, 1999, p. 52). De modo que si las representaciones mediáticas reproducen estereotipos, de manera directa o indirecta, es necesario estudiarlas para analizar qué prejuicios se están reforzando en la sociedad. Según Mauro Cerbino, los medios elaboran representaciones estereotipadas que se basan en dualidades maniqueas que dividen a la población en buenos y malos, los buenos representados por nosotros y los malos por los otros (Cerbino, 2012, p. 82). En el caso de la presente investigación se pretenden conocer los prejuicios que los medios han reproducido con su discurso acerca de la Amazonía para saber si han representado a la región como otra.

En definitiva, es importante estudiar las representaciones mediáticas porque estas constituyen una construcción sesgada y parcial de la realidad. Como afirma Charaudeau: «los medios, si son un espejo, sólo son un espejo deformante... [porque] dan testimonio, cada uno a su manera, de una parcela amplificada, simplificada o estereotipada del mundo» (Charaudeau, 2003, p. 15). Es decir, las representaciones elaboradas por los medios no son una imagen fiel de la realidad. Sin embargo, como ya se dijo antes, estas representaciones, para bien o para mal, constituyen el conocimiento que la gente posee sobre la realidad. En el caso de esta investigación estudiar las representaciones que ha elaborado El Comercio sobre la región a lo largo de las últimas seis décadas permitirá conocer si se ha representado a la Amazonía desde el discurso orientalista.

\section{El discurso orientalista constructo}

\section{de otredad}

Para hablar de Orientalismo es necesario recurrir a Edward Said, quien plantea que el discurso orientalista fue elaborado por Occidente para construir sistemáticamente a Oriente como un otro, y así poder invadirlo y tener control sobre él. Entonces al hablar de discurso orientalista se está hablando de un discurso colonial, cuya función es legitimar los procesos de conquista. En este sentido, los europeos se encargaron de autorepresentarse como los héroes que iban a salvar a los pueblos «bárbaros» de la ignorancia y el caos para supuestamente implantar la civilización (Said, 2008, p. 60-61). Estos conceptos de barbarie frente a civilización fueron tomados desde os cánones de la cultura europea occidental que desvalorizó y echó por tierra la riqueza cultural que existió y que todavía existe en los pueblos no europeos del mundo. Bajo esta lógica se proclama la superioridad cultural de Europa y por ende se infravalora las culturas autóctonas de los pueblos conquistados en América y en Oriente.

Ahora bien, del mismo modo que hace dos siglos el discurso colonial actuaba como legitimador de los procesos coloniales y construía la realidad a su conveniencia; hoy en día el discurso de los medios (o las aquí llamadas representaciones mediáticas) es el encargado de construir la realidad social de los denominados estados moernos, erróneamente autoproclamados como independientes. Y se dice erróneamente porque la independencia implicaría una separación de viejos modos de concebir y pensar la administración de una nación, pero como afirma Bolívar Echeverría los estados modernos de América Latina tomaron a la blanquitud como su identidad racial y cultural fundante. Y por blanquitud debe entenderse al «rasgo identitario-civilizatorio [que] se consolida (...) sobre la base de la apariencia étnica de la población europea noroccidental, sobre el trasfondo de una blancura racial-cultural (Echeverría, 2010, p. 60)

Es por este motivo que el análisis que aquí se plantea pretende deconstruir las representaciones mediáticas para buscar rasgos del discurso orientalista, como un discurso colonial que sigue presente en la vida republicana del Ecuador. Val señalar que se ha escogido al discurso orientalista sobre otros tipos de discursos coloniales porque se sostiene que es el que guarda más relación con el caso aquí estudiado. Así pues, el objetivo macro de esta investigación es Analizar las representaciones mediáticas de la Amazonía que el diario El Comercio ha elaborado durante las últimas seis décadas en sus notas periodísticas para descubrir si dichas representaciones han construido a la región como el oriente ecuatoriano desde el discurso orientalista. Y para poder cumplir con dicho objetivo es necesario revisar a continuación las tres categorías desde las cuales el Orientalismo construye otredad.

\subsection{Categorías de análisis: población} geografía y cultura

Se puede afirmar que el discurso orientalista oper y se expresa en primer lugar desde una dimensión poblacional. Así pues, según Said se concibe a la gente como ignorante pues se desvaloriza los conocimientos que poseen los pueblos originarios, ya que estos no tienen validez ante los ojos de los europeos (Said, 2008, p. 67). De igual forma Boaventura de Sousa Santos señala que la lógica eurocentrista únicamente valora la ciencia moderna basada y regida por leyes universales (De Sousa Santos, 2010, p. 47). Asimismo, de acuerdo con los autores las poblaciones no europeas son consideradas inferiores pues son colocadas en los últimos peldaños de la estratificación social. Esta clasificación aparece supuestamente como natural e imposible de superar con la finalidad de ejercer poder sobre las poblaciones invadidas (Said, 2008; De Sousa Santos, 2010). Por su parte, Ingrid Becker propone que el discurso colonial muestra a los indígenas como naturales para despojarlos de su acervo cultural y de su agentividad social (Becker, 2013, p. 108). Esta oposición s basa en la dicotomía cultura/naturaleza, en donde los europeos son los representantes de la cultura y los nativos de la naturaleza. De esta manera con el análisis se pretende observar si las poblaciones amazónicas han sido representadas come ignorantes, inferiores o naturales por El Comercio.

La siguiente categoría tiene que ver con la concepción del espacio geográfico, la cual es importante al momento de construir al otro porque tiene que ver con el lugar donde habita ese otro. Said señala que la dimensión geográfica adquiere un componente emocional que ayuda a percibir positiva o negativamente un espacio determinado. Así pues, según el autor se tendrá una percep ción positiva cuando el espacio representado sea un espacio cercano, por el contrario cuando se trate de un espacio lejano la percepción será negativa (Said, 2008, p. 87). Por su lado, De Sousa Santos plantea que la noción geográfica pued concebirse desde la improductividad cuando se construye al otro; esto bajo la lógica de produc ción capitalista que considera a las tierras que no producen ganancias como improductivas y/o infértiles (De Sousa Santos, 2010, p. 50). En el discurso orientalista se afirma que antes de la llegada de los europeos los territorios invadidos eran improductivos, porque sus poblaciones no eran capaces de explotar todo su potencial. Este tipo de afirmaciones son las que han justificado las invasiones europeas en el mundo. En el presente trabajo de investigación se analiza las representaciones mediáticas que ha realizado El Comercio para observar si la Amazonía ecuatoriana ha sido representada desde la dimensión geográfica como 
una zona distante e improductiva respecto del resto del país.

La tercera categoría hace referencia al supuesto retraso cultural de los pueblos no occidentales. De esta manera, Said sostiene que el discurso orientalista da por sentado que las culturas no europeas se han quedado en un estadio tardío de la evolución, por tanto, son retrasadas (Said, 2008, p. 77). Según esta visión los pueblos del mundo deben pasar por ciertas etapas para llegar a tener la madurez de Europa, y por ende las culturas no occidentales están rezagadas del progreso ya experimentado por la cultura occidental. A esta perspectiva De Sousa Santos la llama «monocultura del tiempo lineal», pues señala que la idea del retraso cultural de los pueblos no europeos subyace a la lógica eurocéntrica del tiempo lineal, según la cual la historia universal tiene un único sentido y anula la validez de las particularidades culturales de los demás pueblos (De Sousa Santos, 2010, p. 47-48). En el presente estudio se busca visualizar si las culturas de la Amazonía han sido representadas como retrasadas y si su diversidad étnica ha sido desvalorizada desde los cánones occidentales que solo catalogan positivamente a su propia cultura.

\section{El Análisis Crítico del Discurso, propuesta para develar desigualda- des sociales}

Para desarrollar esta investigación se opta por una metodología de carácter cualitativo interpretativ Así pues, el presente trabajo se inscribe dentro de lo que se conoce en el mundo académico como Estudios Críticos del Discurso, o Análisis Crítico del Discurso (ACD). Según Teun Van Dijk el ACD es «un tipo de investigación analítica sobre el discurso que estudia primariamente el modo en que el abuso de poder social, el dominio y la desigualdad son practicados, [y] reproducidos
(...) por los textos y el habla en el contexto social y político» (Van Dijk, 2009, p. 49). Como señala el autor varias formas de inequidad social son susceptibles de ser analizadas en el discurso porque éste es utilizado por las élites simbólicas de la sociedad para legitimar las formas de abuso de poder. Asimismo, Ruth Wodak y Michael Meyer señalan que «el ACD se propone investigar de forma crítica la desigualdad social tal como viene expresada, señalada, constituida, legitimada, etcétera, por los usos del lenguaje» (Wodak \& Meyer, 2003, p. 19). Como señalan Wodak y Meyer, al igual que Van Dijk, la desigualdad social se puede analizar en el discurso, pues un estudio crítico y minucioso permite develar las asimetrías sociales que se esconden en el lenguaje.

De esta manera, es importante realizar un ACD porque las representaciones mediáticas, que se presentan en la información que brindan la prensa, están atravesadas por la opacidad que es una de las características del lenguaje. En ese sentido, Charaudeau afirma: «La información es esencialmente una cuestión de lenguaje, y el enguaje no es transparente; presenta su propia opacidad mediante la cual construye una visión y un sentido particular del mundo» (Charaudeau, 2003, p. 15). Así pues, en esta investigación se realizó un ACD porque las representaciones mediáticas sobre la región amazónica constituyen un discurso que está atravesado por esta opacidad, que es necesario dilucidar para conocer si se ha utilizado el discurso orientalista.

Por otra parte, vale señalar que al hacer un ACD el investigador asume una posición frente al tema estudiado, como afirma Van Dijk: «los ECD no son 'neutrales' (...) por el contrario, están comprometidos a favor de los grupos dominados de la sociedad» (Van Dijk, 2009, p. 26). En este caso el posicionamiento que se toma es a favor de la población amazónica para descubrir si se han realizado representaciones negativas alrededor suyo, que reproducen desigualdad e injusticia social.

Dicho lo anterior es necesario revisar cóm está compuesto el corpus de análisis de esta investigación. Primero hay que decir que se escoge a El Comercio para realizar el estudio por ser un medio de comunicación de alcance nacional que ha estado en circulación 113 años. Durante este tiempo el periódico se ha caracterizado por esta en permanente alianza con las élites económicas y políticas de la serranía ecuatoriana. Esta cercanía al poder le ha permitido posicionarse bien en el negocio mediático a través de su vinculación con otros medios de comunicación como cadenas radiales y televisivas, según lo estableció la Comisión de Auditoría de Frecuencias en 2009. De esta forma, se puede afirmar que el diario históricamente ha producido sus discursos desde el posicionamiento de los grupos dominantes de la sociedad y es por ello especialmente relevante para esta investigación conocer qué representaciones construyó sobre la región amazónica.

Segundo, los periodos de estudio se determinan en base al establecimiento de un hito histórico por cada una de las últimas seis décadas. Se elige este lapso porque se plantea que es a parti de 1964, cuando se expide la primera Reform Agraria, que la región empieza a ser tomada en cuenta como parte del país por su potencial agropecuario y posteriormente por su potencial petrolero y minero, lo cual pone a la Amazonía en la mira de los medios de comunicación. Así pues, como ya se dijo, en la década de 1960 se escoge el año de 1964 porque se formuló la primera Ley de Reforma Agraria del Ecuador que distribuyó tierras al sur de la Amazonía. En los 70 se elige el año de 1972 porque se inició el boom petrolero del país en la zona norte de la región. En la década de 1980 se toma el año 1981 por el conflicto limítrofe entre Ecuador y Perú que se dio en la Cordillera del Cóndor, al sur del país. En cuanto a los 90 se selecciona al año 1993 porque en dicha fecha una comunidad de Sucumbíos (norte de la región) entabló una demanda en contra de la petrolera Texaco por daños medioambientales.

En los 2000 se opta por el año 2007, porque se lanzó la iniciativa Yasuní ITT que buscaba deja bajo tierra el petróleo de esta zona de la Amazonía a cambio de una compensación económica que debía recibir Ecuador por parte de la comunidad internacional con el fin de evitar la contaminación del planeta. Finalmente, en lo que se refiere al último periodo se escoge 2012 por ser el año en el que el proyecto minero «Mirador» consigue la aprobación para la explotación de cobre a cielo abierto en la Cordillera del Cóndor. También, hay que señalar que dentro de estos años se escogen para el análisis cuatro meses, tomando como referencia un mes antes de acontecido el hito, el mes en que se sucedió y dos meses posteriores. Esta decisión se toma porque tras una revisión inicial se encuentra que no existe mayor información sobre la región en los lapsos muy anteriores o demasiado posteriores al hecho marcado como hito histórico. De esta forma, el corpus de análisis queda compuesto por 442 artículos.

Ahora bien, para operativizar esta investigación se elabora una matriz de análisis propia pues como afirma Van Dijk el ACD no constituye en si mismo un método de análisis y sostiene que par realizarlo se pueden emplear múltiples técnicas. Así, el mismo autor propone como una alternativa el análisis estructural del texto (Van Dijk, 2009 p. 184), que es la herramienta metodológica que se utiliza aquí. De esta manera, la matriz de análisis contempla dos elementos: las estructuras no verbales, que permiten indagar las imágenes que acompañaron a las notas, y las estructuras verbales, que ayudan a estudiar el discurso escrito. Las 


\section{Tabla 1: Matriz de análisis utilizada en el estudio}

\begin{tabular}{|c|c|}
\hline №. ficha: & Fecha: \\
\hline Espacio: puede ser $1 / 8,1 / 4,1 / 201$ página completa. & Género: puede ser una noticia, un artículo de opinión u otro. \\
\hline $\begin{array}{l}\text { Sección: puede ser cualquiera de las que está compuesto } \\
\text { el diario. }\end{array}$ & Imagen: se anota si la noticia tiene o no algún tipo de ilustración. \\
\hline \multicolumn{2}{|l|}{ Estructuras verbales } \\
\hline \multicolumn{2}{|l|}{ Titular: se apunta el encabezado de la noticia. } \\
\hline Significado global: & $\begin{array}{l}\text { Se escribe un resumen sobre la noticia para tener una idea general } \\
\text { de su contenido y la principal categoría abordada. }\end{array}$ \\
\hline \multicolumn{2}{|l|}{ Significados locales: } \\
\hline Población: & $\begin{array}{l}\text { Se analiza las representaciones implícitas o explícitas que hace la } \\
\text { noticia sobre población de la Amazonía. }\end{array}$ \\
\hline Cultura: & $\begin{array}{l}\text { Se estudia las representaciones implícitas o explíitas que hace el } \\
\text { artículo sobre las culturas de los pueblos amazónicos. }\end{array}$ \\
\hline Geografia: & $\begin{array}{l}\text { Se examina las representaciones implíitas o explíitas que hace la } \\
\text { nota sobre la geografia de la región amazónica. }\end{array}$ \\
\hline Estructuras no verbales: & Cuando la noticia tiene ilustración se indaga en esta sección. \\
\hline
\end{tabular}

estructuras verbales se analizan a nivel global y local. En el primero se resume la idea general de la noticia y se destaca la principal categoría abordada en la nota. El segundo ayuda a analizar la noticia detalladamente y a estudiar cómo se representa a cada una de las categorías analíticas: población, geografía y cultura. Vale apuntar que específicamente en la categoría población se presume que se podría haber usado lo que Van Dijk llama cuadrado ideológico, que es estrategia discursiva que consiste en maximizar los aspectos negativos de los otros al mismo tiempo que se minimizan sus aspectos positivos; mientras que se maximizan los aspectos positivos de nosotros y se minimizan los negativos (Van Dijk, 2005, p. 30)
Por último, hay que indicar que con el propósito de organizar las fichas de análisis se incluyen en las primeras casillas datos como: fecha de la publicación, sección y página donde se publicó, espacio que le fue destinada, género periodístico utilizado y titular. Hecha esta salvedad, la matriz de análisis queda graficada de la siguiente manera:

\section{Resultados}

Los resultados que se presentan son producto de la aplicación de la matriz de análisis a 442 por El Comercio durante las últimas seis décadas. Vale advertir que los hallazgos encontrados se expondrán por categoría analítica. artículos referentes a la Amazonía, publicados

\section{Los habitantes amazónicos como los otros}

\section{dentro del país}

Durante la década de los 60 y 70 el medio se dedica a representar positivamente a la población denominada colona, es decir, a los mestizos que llegan a vivir en la región; mientras que la población originaria es poco visibilizada y cuando aparece es mostrada negativamente. Un ejemplo de ello es la noticia titulada «Ruinas Arqueológicas del Oriente Ecuatoriano», en ella se encuentran expresiones como la siguiente:

En la parte centro Norte [de la Amazonía], lo RR.PP. Josefinos han descubierto sorprendentes y enigmáticos restos de edificaciones construidas con enormes piedras sillares. Estas civilizaciones totalmente desaparecidas y dignas de una metódica exploración, nada tienen que ver con los jibaros y demás tribus del actual Oriente Ecuatoriano, tod estas aún en pleno primitivismo (El Comercio, 24 de junio de 1964)

Como se puede observar opera aquí el cuadrado ideológico ya que la nota hace una alusión negativa de los indígenas amazónicos a llamarlos «jibaros» y decir que se conservan en pleno «primitivismo», con esto se los representa como ignorantes, inferiores y naturales pues se los muestra como seres sin conocimiento, se los ubica el peldaño más bajo de estratificación social y se los despoja de su acervo cultural y su agentividad social. De igual manera, al señalar que anteriormente en esas tierras habitaban civilizaciones se hace referencia a la monocultura europea occidental que cree que el desarrollo y progreso tienen una única dirección marcada por estadios (De Sousa Santos, 2010). En base a ello la cultura de los indígenas amazónicos se presenta como retrasada, pues explícitamente se dice que en dicha zona antes existía una civilización que nada tiene que ver con los actuales indígenas que habitan este territorio. Posteriormente se hacen afirmaciones sobre la causa de la desaparición de las llamadas civilizaciones y se dice:

En cuanto al capítulo de la arqueología más reciente, ofrece particular interés la exploración de las ruinas de una docena de ciudades o villas de la Colonia Española, confundidas en esas selvas Amazónicas, más o menos próximas a las cordilleras. Todas fueron del siglo XVI, el siglo de la Conquista y expansión, y desaparecieron violentamente a raíz de la feroz acometida a sangre y fuego, por parte de los salvajes jibaros, que cayeron casi al mismo tiempo sobre todas ellas (El Comercio, 24 de junio de 1964).

Con estas afirmaciones aparece explícitamente el cuadrado ideológico porque se hace una exaltación al proceso de conquista mostrando positivamente a los colonizadores; y al mismo tiempo se enfatizan en los aspectos negativos de los amazónicos al mostrarlos como seres violentos que destruyeron la «civilización» que los españoles intentaban implantar en la zona. De igual manera, se observa que se pone a la cultura europea como el modelo a seguir, mientras que se menosprecia y se trata como culturas retrasadas a las originarias de la región.

En los años 80 se empezó a hablar más de los indígenas, pero manteniendo una representación negativa. En este sentido, se publica el reportaje «Región Amazónica: esperanza, dolor, promesa...». Este artículo se publica con motivo de celebrarse el 75 aniversario del diario y en él se hace un repaso histórico sobre la región. Así pues, se recoge uno de los contratos de colonización suscritos en la época republicana, el mismo que dice:

«A la misión Salesiana en sus representantes de varios centros misionales se da la personería legal de los jibaros, durante el periodo de veinticinco años a partir de la fecha». Mediante decreto de 5 de junio de 1946, «los religiosos salesianos se comprometieron para la colonización y culturización del oriente ecuatoriano, dentro de los límites del vicariato apos- 
tólico de Méndez y Gualaquiza; a fundar o apoyar la fundación de colonias de blancos y de jibaros, especialmente en la proximidad de la línea fronteriza meridional y oriental» [comillas en el original] (El Comercio, 01 de enero de 1981).

En este párrafo se representa a la población de la región como ignorante, inferior y natural porque se dice que los Shuar (mal llamados «jíbaros» en el artículo) fueron puestos en custodia de los salesianos para «civilizarlos», con lo cual se sugiere que la población originaria no poseía la capacidad intelectual ni social para conducir sus acciones y, asimismo, se niega la existencia de una organización social propia de los nativos. De modo que se los despoja de su acervo cultural y su agentividad social pues se niega la existencia de cultura dentro de estos pueblos y es por ello necesario «cultivarlos» según la noticia.

Otra nota que vale destacar es un artículo publicado bajo el título: «25 años de la matanza de misioneros por los aucas». En esta noticia se habla de un hecho sucedido en 1956 donde murieron 5 misioneros evangelistas. De esta forma, se dice:

Un holocausto por el ideal de divulgar un credo religioso concitó hace veinticinco años el interés mundial sobre la geografía y gente del Ecuador: la matanza de cinco jóvenes predicadores evangelistas por los indómitos aucas, aborígenes de la región amazónica. La masacre a lanzazos y machetazos se produjo cuando los intrépidos misioneros penetraron por primera vez en los dominios de los feroces nativos con el fin de evangelizarles (El Comercio, 25 de enero de 1981).

Como se puede observar en este párrafo se representa a la población como inferior, ignorante y natural al utilizar términos como «indómitos, aborígenes y feroces» para describir a los amazónicos. Aquí se utiliza el cuadrado ideológico para resaltar las cualidades negativas de los Huaorani (peyorativamente llamados «aucas») al mostrarlos como violentos; al mismo tiempo se destacan los valores positivos de los evangelistas al referirse a ellos como «intrépidos», ya que con esto se quiere decir que fueron valientes al ingresar a la Amazonía. Así pues, se muestra a los indígenas como victimarios y a los misioneros como las víctimas de un «holocausto».

Este tipo de noticias defienden los procesos colonizadores efectuados en la zona, porque en ningún momento se cuestiona el papel opresor del cristianismo sobre los indígenas amazónicos que ha operado en la zona durante siglos. Muestra de ello es el poder que tienen las misiones religiosas en la Amazonía hasta la actualidad. Pero bajo la lógica occidental asumida por el Ecuador republicano esto no es un tema que deba discutirse porque se tiene interiozada la blanquitud como rasgo identitario (Echeverría, 2010), y por ende se ve como necesario el blanqueamiento cultural de las poblaciones indígenas.

En los 90 a nivel global se empieza a hablar de los problemas medioambientales a raíz de la Cumbre de las Naciones Unidas sobre Medio Ambiente y Desarrollo efectuada en 1992 en Río de Janeiro. Así pues, en 1993 las noticias de El Comercio abordan los temas del medio ambiente relacionándolos con las consecuencias de la explotación petrolera en la Amazonía.

En este sentido, aparecen noticias como «Petróleo y deterioro ambiental» donde se dice: «En la Amazonía ecuatoriana podemos ver que el desarrollo petrolero, a pesar de resultar lucrativo para algunos, está causando pobreza entre los indígenas y aumentándola entre los colonos; además de provocar un grave deterioro del medio mbiente» (El Comercio, 20 de septiembre de 1993). Con esta información se hace evidente que a población de la región lejos de beneficiarse de la explotación petrolera se ha visto perjudicada. Sin embargo, se termina representando a la población como inferior, pues se dice que la gente que habita en la Amazonía está sumergida en la pobreza de forma generalizada, y vale recordar que la condición de pobreza ubica a las personas en el último puesto de la clasificación social. Posteriormente, se habla de la forma en la que afecta el deterioro ambiental a la población y se afirma:

Los pozos petroleros existentes generaran más 4,3 millones de galones de desechos tóxicos a diario, que en su mayoría son descargados al medio ambiente y contaminan ríos y esteros, que son utilizados por los habitantes del sector, que suman entre unas 350 y 500 mil personas (...) [Además] bioacumulación de petróleo en los alimentos pued afectar seriamente la salud humana (El Comercio, 20 de septiembre de 1993).

Con esta información se recalca lo grave que resulta el mal manejo de desechos provenientes de las actividades petroleras pues, como señala la nota, ocasiona afecciones a la salud de la población que se provee de aguas y alimentos contaminados. Lo que no se dice es que esto problemas también se relacionan con la falta de servicios básicos en los poblados amazónicos, ya que si la gente contara con agua potable no tendría la necesidad de beber directamente el agua de los ríos. Además, las plantas de tratamiento procurarían que sus fuentes hídricas estén bien cuidadas, sin exposición a sustancias tóxicas. De modo que los problemas que se ocasionan en la naturaleza y que perjudican a la población tienen sus raíces en la desatención estatal que ha sufrido por décadas esta región, convirtiéndola en la menos atendida frente a las demás. Sin embargo, esto no se apunta en la noticia. Lo que sí se hace con esta información es representar a la población como vulnerable porque la contaminación del ecosistema es una amenaza para su salud.

En la primera década de los 2000 llama la atención las noticias que empiezan a hablar so- bre los pueblos no contactados de la Amazonía llamados en décadas pasadas «temibles aucas». Como ejemplo está el artículo «Los pueblos no contactados siguen en riesgo». La noticia cuenta que Petrobras realizó un taller para socializar su propuesta de lineamientos de actuación en caso de contacto con los pueblos en aislamiento voluntario. Así pues, resulta interesante que la noticia comience diciendo: «A dos meses de cumplirse cuatro años de la matanza del Tingüino ya casi nadie lo recuerda. Pero expertos como el sacerdote Miguel Ángel Cabodevilla mantienen el temor de que este trágico suceso se repita en cualquier momento» (El Comercio, 02 de marzo de 2007).

Más adelante en la noticia se señala que se trató de un enfrentamiento entre poblaciones indígenas ocurrido en 2003 que tuvo como resultado la muerte de 20 personas, y se utiliza el término «matanza» para describir el acontecimiento. En este sentido, se puede decir que de forma implícita se da a entender que los pueblos no contactados son agresivos. De esta manera, se representa a la población como natural pues dice que los nativos actúan con violencia y se los despoja de su acervo cultural.

Más adelante se cuenta cómo Petrobras va a manejar el tema de los encuentros con los indígenas y se afirma: «Según Alejandra Rivas, gerente de Relaciones Internacionales de Petrobras, el proyecto de esta compañía apunta a minimizar la posibilidad de un encuentro accidental o forzoso con los pueblos en aislamiento voluntario 'Para eso se capacitará al personal' [dijo Rivas]» (El Comercio, 02 de marzo de 2007). Con esta información se dice que se evitará el contacto con las comunidades indígenas, pero no se aclara por qué; sin embargo, contextualmente se puede deducir que el motivo es el miedo que se tiene a los pueblos nativos, pues la noticia los describió anteriormente como violentos. Esto contribuye 
a representar a los indígenas amazónicos como naturales, pues de forma latente se afirma que son violentos, peligrosos y que no poseen cultura.

Posteriormente, se habla de cuáles son los riesgos que corren los indígenas al tener contacto con personas de la petrolera y se dice:

una de las mayores amenazas para esta gente [se refieren a los indígenas] es el contagio de enfermed des (...) Son víctimas fáciles porque sus cuerpos no tienen las suficientes defensas, además para llegar hasta ellos con las medicinas se requiere de varios días de camino (El Comercio, 02 de marzo de 2007).

Este párrafo afirma que lo peor que los foráneos les pueden hacer a los indígenas es contagiarles alguna enfermedad, lo cual en realidad es algo fortuito e involuntario. Así pues, se observa aquí el uso de cuadrado ideológico. En este sentido, se enfatiza en los aspectos negativos de los indígenas que son los otros, de quienes se dice que son violentos y provocan «matanzas». Y, por otro lado, están las empresas petroleras que representan al nosotros, cuyo impacto sobre las comunidades es minimizado al decir que lo más grave que ellas pueden hacer es contagiar una enfermedad a los nativos. Con todo esto lo que se hace es representar negativamente a los indígenas y positivamente a las petroleras. Entonces, esta nota construye a los pobladores amazónicos desde la otredad.

En el último periodo continúan las representaciones negativas sobre la población, aunque de forma más implícita. De esta manera, aparecen reportajes como «Padres e hijos estudian a distancia». Este artículo cuenta que varias comunidades de la provincia de Orellana estudian con el sistema a distancia que oferta la Unidad Educativa Fiscomisional Yachana Inti. Así pues, se señala: «Hay dos especialidades: ciencias sociales y agropecuario forestal en dos tipos de programas académicos. El uno está dirigido a las comunidades indígenas y actualmente suman 948 estudiantes kichwas, shuar y huaoranis» (El Comercio, 25 de marzo de 2012a). Con esta descripción se muestra a la población indígena de forma positiva pues se afirma que se están preparando académicamente. Esto es bien visto desde la perspectiva occidental pues se proclama la idea de que educación formal es fundamental para el progreso de los pueblos.

No obstante, cuando se cuenta la historia de Orfa Tapuy y Edwin Andi, una pareja indígena que estudia en este colegio, las representaciones se tornan menos favorables para la población. En este sentido, se dice: «La joven pareja recibe las tutorías en la extensión del Yachana Inti de esa localidad [San José de río Coca] y optó por esa forma de estudio porque no tienen dinero para cubrir los gastos en otro colegio» (El Comercio, 25 de marzo de 2012a). A pesar de que la intención tal vez sea resaltar que en medio de las carencias la gente se está preparando, lo que se termina haciendo con esta narración es representar a la población como inferior porque se afirma que vive en la pobreza y como ya se dijo esta condición ubica a la gente en los últimos peldaños de la clasificación social. Con este mismo tono se recoge la historia de otra familia de la zona y se dice:

Debido a esta dificultad de traslado, Gonzalo Noteno y Nubia Salazar pusieron a tres de sus $11 \mathrm{hi}-$ jos en Yachana Inti de San José de río Coca, en el primer programa de educación. El dinero escasea en el hogar y esa fue la razón de que los demás no estudiaran (El Comercio, 25 de marzo de 2012a).

Con esta narración se representa a la población como inferior nuevamente ya que se describe que la gente es pobre, lo cual la ubica en el último puesto de la estratificación social. Asimismo, se asevera que es la pobreza la que impide que muchos integrantes de una familia accedan a educación, esto los representa como ignorantes debido a que según la perspectiva occidental la falta de escolaridad le da a una persona la condición de ignorante. De esta manera, lo único que hace este tipo de notas es construir a los pobladores amazónicos como otros, al mostrarlos como ignorantes, inferiores y naturales. Pero, en ningún momento se hace un cuestionamiento a las autoridades de Educación para que inviertan en infraestructura y personal educativo, y que se cumpla así con el derecho a la educación que está estipulado en la Constitución de la República, pero que todavía los amazónicos no pueden gozar. Esto ocurre porque en realidad la educación gratuita y de calidad sigue siendo un privilegio en Ecuador.

Las tierras de la Amazonía como distantes y peligrosas, pero a la vez fértiles y

\section{productivas}

En la década de los 60 las noticias están encaminadas a representar a la geografía como fértil con la intención de mostrar a la región como la zona más propicia para el desarrollo de la primera Ley de Reforma Agraria. En este sentido aparecen notas como la titulada: «Proyecto de INC para la colonización del Valle del Río Upano está en marcha». En ella se cuenta que se está preparando un proyecto para llegar a las tierra de la Amazonía con la intención de habitar en ellas. Así pues, de manera explícita se dice que el objetivo del proyecto es «aliviar la grave presión demográfica actual en las provincias del Azuay y Cañar, canalizando sus excedentes hacia el fértil Valle del Río Upano» (El Comercio, 02 de junio de 1964). En estas breves líneas se puede observa dos cuestiones: por un lado, de forma explícita se dice que las tierras de oriente son fértiles; po otro lado, implícitamente se las muestra como improductivas porque aparentemente no existe el contingente humano que las haga producir, lo cual hace que su colonización sea necesaria según la nota.
Posteriormente, se dice: «Para esto [poder ocupar el Valle del Upano] (...) se considera de importancia la terminación de la carretera Paute Méndez - Macas - General Proaño» (El Comercio 02 de junio de 1964). De este fragmento se puede inferir que la zona no es de fácil acceso pues la carretera que conduce hacia el lugar todavía está en construcción, lo cual la convierte en una zona lejana. Por lo tanto, se representa a la geografía como distante.

Otra forma de representar a la geografía de la región es como peligrosa. Ejemplo de este tipo de representación es la noticia titulada «Desbordamiento de ríos en región de Canelos acarreó tragedia a los habitantes». La nota trata sobre el desbordamiento del río Bobonaza, cercano a la población de Canelos en la provincia de Pastaza. De esta manera, se narra la historia de una familia que perdió a tres miembros debido a este desastre natural. De modo que se reseña:

Las aguas del Bobonaza cubrieron totalmente la cas de la indígena Magdalena Aranda de Canelos y en pocos minutos la edificación fue llevada por el río flotando como embarcación con todos sus ocupantes en el interior, la indígena Aranda de Canelos y sus cinco hijos menores de edad. Después de recorre un largo trecho la casa que flotaba, mientras sus ocupantes lanzaban gritos de auxilio, se destruyó y desaparecieron en las turbulentas aguas tres niños, que perecieron ahogados. Los tres ocupantes lograron sobrevivir aferrándose a los maderos que eran arrastrados por el río. La joven Guadalupe Canelos, de 14 años de edad, fue rescatada en el sitio denominado «Chapetón» a cinco horas río abajo desde Canelos. El menor Venancio Canelos, de 12 años fue encontrado y salvado en «Tilanhuay» a cinco horas y media río abajo. Magdalena de Canelos fue rescatada en las inmediaciones de la localidad de Pacayacu a nueve horas río abajo desde la población de Canelos. Estas personas recibieron atención y luego, pese a las dificultades fueron llevadas nuevamente a Canelos (El Comercio, 30 de septiembre de 1964). 
Con esta crónica se hace alusión a la peligrosidad de la zona, pues la nota relata la violenta forma en que la naturaleza le quitó a una familia su casa y parte de sus integrantes. Narraciones de este tipo ayudaron a construir una imagen negativa de la región, pues según la noticia vivir en la Amazonía resulta toda una aventura porque la gente está expuesta a que sucedan este tipo de acontecimientos en cualquier momento.

Finalmente, la nota dice:

La mayoría de las canoas de los indígenas y colonos de toda la zona fueron destruidas por la creciente y actualmente carecen de los medios de movilización por los ríos, único sistema para comunicarse y realizar el comercio en toda la extensa zona (...) Los pequeños caminos de herradura prácticamente desaparecieron y la que une Veracruz con Canelos se halla intransitable, pues se han formado grandes lagunas, se destruyeron puentes y en algunos sitios ha sido borrado el camino (El Comercio, 30 de septiembre de 1964).

Estos párrafos dan cuenta de que los pueblos de la Amazonía carecen de conexión vial entre sí, lo cual los muestra como distantes. Con una fuerte lluvia los pueblos quedan desconectados, incomunicados. Asimismo, se observa la falta de planificación de los asentamientos de las colonias porque es eso lo que hace que estén expuestos a las consecuencias de los desastres naturales. Esta situación permite afirmar que la región ha sido desatendida por las autoridades nacionales, pues poco o nada se ha hecho por brindar infraestructura y servicios a la Amazonía; sin embargo de ello no se habla en la noticia, lo único que se hace es construir una imagen negativa de la región.

Mostrar a la Amazonía como un lugar peligroso es la tónica de las noticias durante todos los periodos estudiados, así en los 70 siguen apareciendo publicaciones en este sentido. Una muestra de esto es la nota « 3 muertos al naufragar una canoa en río Coca». En esta se habla de un accidente en el río Coca que dejó como consecuencia 3 víctimas. De esta manera, se dice:

Washington Ibarra, oriundo de la población de Borja, se hallaba acompañando a dos estudiantes de otra provincia que se hallaban de viaje por ese lugar (...) Washington Ibarra se atrevió a conducir la pequeña embarcación de madera (...) Mas, a mitad de camino, una fuerte correntada arrastró la canoa aguas abajo (...) Hacia abajo, la corriente del río que se desliza en forma más precipitada, volteó la canoa, de la cual se agarraron en un principio los tres ocupantes. No obstante, la fuerza de las aguas, los separó más tarde del madero, meciéndolos instantáneamente hasta que desaparecieron en medio de las correntosas aguas del río que sepultó sus cuerpos (El Comercio, 30 de mayo de 1972a).

Con esta narración del accidente se pone énfasis en los riesgos de viajar por la región pues se afirma que transportación fluvial es insegura. Así pues, se muestra a la geografía como peligrosa porque se dice que los ríos de la región tienen «aguas correntosas», lo cual hace a la zona propensa a que sucedan este tipo de accidentes. Asimismo, se la representa como distante porque de forma implícita se señala que la Amazonía carece de infraestructura vial, lo cual hace que los procesos de comunicación y transporte sean demorados. Además, hay que recordar que la distancia hace que los territorios lejanos no sean percibidos como nuestros (Said, 2008)

Por otro lado, en esta década la región empieza a ser vista como una zona petrolera por las grandes reservas de crudo que se encuentran en el subsuelo. Así aparecen notas como: «Hace 3 años señalose la obligación de construir oleoducto». Aquí se habla sobre la exploración petrolera en a región que determina la existencia de recursos hidrocarburíferos susceptibles de ser explotados. De este modo se señala:
El primer pozo productivo, el Lago Agrario $\mathrm{N}^{\circ} 1$, fue perforado en la concesión Napo, a 180 kilómetros al Este de Quito y a 15 kilómetros del campamento Santa Cecilia. Su producción inicial fue de 2.500 barriles por día. Hasta finales de julio de 1970 se había perforado 32 pozos, de los cuales 30 resultaron productivos; el mayor de todos, probado en do zonas de producción, arrojó 2.621 barriles diarios en una zona, y 2.494 barriles en otra (El Comercio 24 de junio de 1972).

Con esta información se hace una representación positiva de la zona pues se dice que posee petróleo, valioso recurso natural que tiene un importante apreciación económica en el mercado mundial. Así pues, la explotación petroler significa réditos económicos para el país, lo que representa a la región como productiva. Vale deci que cuando inicia el boom petrolero se cree que este recurso sacará al Ecuador de la pobreza, cosa que no ha sucedido hasta el momento. De todas maneras, se comienza a apreciar las riquezas naturales de la región.

En los 80 el conflicto limítrofe con Perú suscitado al sur de la Amazonía muestra a la región como una zona alejada y desconocida. Ejemplo de ello es el artículo titulado: «La Cordillera de Cóndor». En este se cuenta que la zona permaneció oculta durante mucho tiempo para el propio país. Así se dice:

Los geógrafos antiguos, y los modernos hasta primera mitad del siglo XX, cuyas investigaciones fueron mediante largos y fatigosos reconocimientos terrestres, no sabían de su existencia [se refiere a la cordillera de El Cóndor], por eso, los insignes Alejandro Humboldt y Teodoro Wolf, precursores de la geografía ecuatoriana, en ninguno de sus estudios mencionan a esta cordillera subandina, porque al tiempo de sus recorridos, la selva amazónica era incógnita inaccesible, y solamente los misioneros religiosos se aventuraban a ingresar en ella en cumplimiento de su abnegación vocacional de evangelizar a los infieles salvajes (El Comercio, 30 de enero de 1981).
En este párrafo se puede observar dos cuestiones interesantes sobre cómo se representa a la geografía y a la población amazónica. En primer lugar, la geografía se presenta como distante pues se utilizan las palabras «incógnita e inaccesible» para referirse a ella. Asimismo, se dice que es desconocida pues amplios sectores no constaban ni siquiera en la cartografía del país. Esto ayuda a concebir a la zona como distante, alejada, no perteneciente a lo nuestro. Y esto tiene una repercusión negativa en la percepción de los espacios como lo señala Said (2008). De esta manera, al ser la Amazonía un lugar lejano es percibido como un espacio ajeno. En segundo lugar, se dice que dicho espacio vive una población otra que es llamada «infiel»y «salvaje», expresiones que sirven para representar a los indígenas como ignorantes, inferiores y naturales, y así completar la idea de un espacio distante que les pertenece a ellos y no a nosotros.

En los 90 la corriente ambientalista derivada de la Cumbre de Río de Janeiro hace que el diario cubra temas relacionados con el medio ambiente como la demanda que interponen los indígenas amazónicos en contra de la petrolera Texaco; aunque no le hacen un seguimiento adecuado al tema. Así pues, se publica la nota «Texaco, enjuiciada». Esta noticia cuenta que el

03 de noviembre las comunidades indígenas de la Amazonía ponen una demanda en contra de Texaco por daños al medio ambiente. En este sentido se recogen declaraciones de Elías Piyaguaje representante de la comunidad Secoya, quien dice: «no podemos tomar agua de los ríos ni para beber ni para lavarnos, y los animales se están extinguiendo» (El Comercio, 05 de noviembre de 1993). Con esto se representa a la geografía y a la población como vulneradas pues se ha afectado las condiciones de la naturaleza al contaminarla 
y esto ha ocasionado que el bienestar de la población se vea perjudicado.

Más adelante se recogen declaraciones de Chris Jocnick, uno de los autores del estudio sobre la afectación ambiental causada por la actividad petrolera a la Amazonía ecuatoriana. Dicha investigación la realizó el Instituto de Economía y Derechos Sociales (IERS por sus siglas en inglés) de EE. UU. En este sentido se apunta:

Según Jocnick, los análisis preliminares realizados tomando muestras de agua y suelo, en las zonas donde operó Texaco demuestran la presencia de sustancias tóxicas (...) en cantidades peligrosas y que van en contra de los niveles de tolerancia dispuestos por la Agencia de Protección del Medio Ambiente de los Estados Unidos (...) En el estudio realizado por el IESR se anota que 12 personas fueron examinadas por facultativos médicos y se diagnosticó que padecían de dermatitis y lesiones cutáneas. Todos los pacientes habían mantenido contacto con aguas altamente contaminadas por desechos tóxicos (El Comercio, 05 de noviembre de 1993).

De acuerdo con lo señalado por los expertos se hace evidente que la petrolera Texaco no cumplió con la normativa ambiental, lo cual generó estragos en la naturaleza y por ende en la población de la región. Así pues, la geografía y la población son representados como vulneradas. En el caso de la geografía se dañó sus cualidades naturales al contaminarla. Y en el caso de la población se afectó su bienestar pues como consecuencia de la polución su salud está deteriorada.

Posteriormente, se hace referencia a la auditoría ambiental que se le hace a la empresa para determinar si había o no causado perjuicio en la región amazónica. Así se señala: «La auditoría debió concluir a mediados de septiembre de 1993, empero, se desconocen los resultados de la misma, pese a que en el contrato se establece la elaboración de un informe quincenal sobre la marcha del proceso»
(El Comercio, 05 de noviembre de 1993). Con esto se insinúa que existe irregularidades en la auditoría, lo cual hace pensar que no hay transparencia ni celeridad en la forma como se está llevando el proceso. Finalmente, se mencionan algunos grupos que están trabajando para que se esclarezca el tema de la auditoría y se dice:

Grupos ambientalistas de Ecuador y Estados Unidos han cuestionado la auditoría por falta de información pública, exclusión de las poblaciones afectadas y porque los términos de evaluación fueron determinados entre Petroecuador y Texaco. No se puede ser juez y parte a la vez, afirman (El Comercio, 05 de noviembre de 1993).

De esta manera, se dice que son los mismos que operaron en la zona quienes pretenden evaluar su propia actuación. Esto indica que la auditoría no es del todo confiable pues como señala la nota no se puede ser juez y parte dentro de un proceso de este tipo. De tal manera que la información hace dudar de la transparencia de los resultados que arroje la auditoría.

En esta noticia se puede observar la contundencia del medio al señalar la responsabilidad de la petrolera sobre los daños medioambientales causados a la región. Sin embargo, el tema no se sigue por mucho tiempo, luego de esta noticia no existen más que aborden directamente el tema. Después de esta publicación la preocupación del medio es cómo afecta esta demanda las relaciones comerciales del país con la gran petrolera estadounidense. Así pues, no existe un compromiso por apoyar la demanda de los indígenas, que hasta hoy no ha sido resuelta de forma definitiva; $y$ cuyos daños siguen generando problemas al entorno natural y a la población de la región amazónica.

En la primera década de los 2000 se empieza a contemplar otros planes para las reservas petroleras del Ecuador con la iniciativa Yasuní
ITT. Así se publica la nota: «4 escenarios para el mayor campo petrolero del país». Desde el título se puede observar que se representa a la geografía como productiva pues se afirma que en ella se encuentra las mayores reservas de petróleo de país, lo que significa altos réditos económicos. Luego, en el cuerpo de la noticia se señala que se estudian cuatro posibilidades para aprovechar los recursos existentes en este campo petrolero. En este sentido se dice:

El Ministerio de Energía y Petroecuador definieron las opciones para el campo Ishpingo-TambocochaTiputini (ITT). Primera: no explotar crudo, si la comunidad internacional entrega fondos por el $50 \%$ de su explotación. Segunda: producir con recursos propios. Tercera: explotar el crudo con otra petroleras estatales. Cuarta: convocar a licitación internacional (El Comercio, 31 de marzo de 2007).

Con esta información se representa a la zona como productiva porque todas las opciones incluyen la ganancia a cambio de los recursos que existen en la región. En el caso de que el crudo se quede bajo tierra se pretende una compensación internacional por cuidar al medio ambiente de la zona, lo cual tiene una repercusión positiva nivel mundial pues se evita la emisión de gases de efecto invernadero. Y en el caso de las otras tres opciones que contemplan explotar el petróleo a través de diferentes mecanismos, la ganancia sería obtenida de manera tradicional, dinero a cambio de petróleo, que es la forma en la que se ha manejado el tema en el país. Entonces, esta noticia representa a la región como productiva pues se afirma que de cualquier modo las riquezas de la Amazonía significan beneficio económico para el Ecuador. Además, hay que decir que el tema petrolero ha servido para mostrar a la zona como productiva desde la década de los setenta.

Finalmente, en el último periodo estudiado se encuentra el turismo como un tema desde el cual se elaboran representaciones de la geografía de la región. De esta manera, se publica el reportaje: «La naturaleza seduce en Lumbaqui». La nota relata que la provincia de Sucumbíos cuenta con varios atractivos turísticos. En este sentido se dice:

Un clima cálido y húmedo, paisajes verdes, aves cantando y varios senderos por recorrer. Eso ofrece la parroquia Lumbanqui, en el cantón Gonzal Pizarro, de Sucumbíos. Allí, se destaca un lugar pequeño, pero atractivo que encierra mística que atrae a los visitantes. Es la piedra de los monos (...) E acceso es sencillo para los turistas. El primer tramo se recorre en automóvil y luego se hace una caminata de 15 minutos aproximadamente (El Comercio, 04 de febrero de 2012)

De esta manera, se representa a la región como productiva y cercana. En primer lugar, se la muestra como productiva porque se menciona lugares que resultan propicios para el desarrollo de actividades turísticas, lo cual significa ganancias para la gente de la zona. En segundo lugar, se señala que es cercana porque estos atractivos turísticos cuentan con fácil acceso para que los viajeros puedan visitarlos. Luego, se describe un parador turístico denominado Los Manantiales y se dice:

También es posible bañarse en el río que rodea a Los Manantiales. A las mujeres les gusta hacerlo antes de la cascada porque las paredes del afluente están compuestas de arcilla, pues se la untan sobre la piel. Según los propietarios de este lugar, esta arcilla tiene una función limpiadora y deja la piel libre de impurezas y suave (El Comercio, 04 de febrero de 2012).

En este párrafo se indica las propiedades benéficas de los recursos naturales de la zona. Esto constituye otro atractivo para los turistas, po lo cual se vuelve a representar a la zona como productiva. El desarrollo de actividades turísticas significa para la población la oportunidad de mejorar su economía. Hasta el momento la nota 
tiene un tono positivo; sin embargo, más adelante vuelven a aparecer las representaciones negativas. Así pues, cuando se hacen algunas recomendaciones para realizar el paseo a la zona se señala:

Es aconsejable llevar zapatos de caña alta y de buen labrado, porque el terreno es resbaladizo y en el camino pueden aparecer animales venenosos. No se debe tocar a los animales silvestres ni apoyarse a los árboles, ya que pueden causar afectaciones a la piel y a la salud (El Comercio, 04 de febrero de 2012).

Con esta información se representa a la geografía como peligrosa porque se dice que los visitantes están propensos a sufrir caídas debido a lo irregular del suelo. Asimismo, se dice que los turistas pueden sufrir picaduras de animales venenosos y ser contagiados de alguna enfermedad por el simple hecho de tener contacto con especies de flora y fauna de la región. Esto constituye una representación negativa, lo cual lejos de ayudar a la actividad turística puede ahuyentar a los visitantes porque resulta poco atractivo viajar a un lugar donde se puede sufrir algún tipo de accidento o contraer una enfermedad. De este modo, hay que señalar que se sigue viendo a la Amazonía como una zona riesgo, poco habitable, desconocida y distante, todo ello tiene una repercusión negativa en la forma de percibir el espacio como lo sostiene Said (2008).

\section{Las culturas de las nacionalidades amazónicas}

\section{como retrasadas}

Las culturas de la Amazonía se representan como retrasadas en las publicaciones de El Comercio de las últimas seis décadas. Así pues, durante todos los periodos estudiados se utiliza la carencia de servicios básicos como un tema para mostrar el retraso en el que viven las poblaciones de la región. En este sentido, en la década de los 60 se publican notas como: «Sector central de El Puyo está sin servicio de luz eléctrica». Esta no- ticia habla de la categoría cultura desde la idea de progreso/retraso y cuenta que Puyo, capital de la provincia de Pastaza, se encuentra más de quince días sin servicio de electricidad lo cual ha perjudicado a los centros de enseñanza nocturna que funcionan en el sector. En este sentido, la publicación dice:

El sector central de esta población ha permanecido sin servicio eléctrico desde hace más de quince días por haberse quemado un transformador, ocasionándose así graves molestias a la ciudadanía. La situación se agrava porque en dicho sector funcionan el Colegio Técnico de Señoritas «Nuestra Señora de Pompeya»; las Escuelas Álvaro Valladares, Vacas Galindo, y Santo Domingo de Guzmán; y el Hospital de la Cruz Roja. Además, la Misión Dominicana mantiene tres centros de alfabetización, los que no pueden laborar por las noches por la falta de luz eléctrica (El Comercio, 17 de julio de 1964).

Así pues, se muestra a la región como retrasada por tener falencias en la prestación de servicios básicos a la población, en este caso el servicio de energía eléctrica. Es así como actúa la dicoomía progreso/retraso, quienes están integrados al desarrollo tecnológico son parte del progreso y quienes están fuera de él están sumergidos en el retraso (De Sousa Santos, 2010).

En los 70 se empieza a hablar de las nacionalidades indígenas de la Amazonía con noticias como la titulada «Exposición amazónica del Ecuador se inauguró en San Antonio de Pichincha». En esta se habla de una exhibición que intenta recrear los modos de vida de la región Amazonía. Así pues se dice:

Como centro de atracción principal de la Exposición Amazónica, figura la choza de una familia jíbara típica. Las cañas guadúas, los maderos, la paja que cubre el techo, las ligaduras vegetales que arman la choza, las armas, redes, vasijas, etc., son todas genuinas de la zona de Canelos. Un indíge- na de esta zona hizo la construcción mediante los sistemas propios de su tribu (El Comercio, $30 \mathrm{~d}$ mayo de 1972b).

La nota se refiere a la población nativa como «jibaros», es decir, se la representa como inferior, jamás se hace referencia al nombre la nacionalidad de los indígenas, sino que siempre se los estereotipa como jíbaros, dejando de reconocer la diversidad étnica que existe al interior de la región, y, por lo tanto, desconociendo la riqueza cultural de estos pueblos. Asimismo, para referirse a ellos como colectivo se los llama «tribu», esto representa a la población como natural pue se le despoja de su acervo cultural y agentividad social. De modo que se puede afirmar que con esa narración el medio niega la existencia de cultura en las nacionalidades indígenas de la Amazonía.

Posteriormente, la nota relata: «En el centro de la habitación está un jefe jíbaro, tallado en madera, con atuendos de fiesta o de guerra, con petos de corteza de árbol, plumas vistosas coronada en un penacho $u$ adornos de semillas y huesos (El Comercio, 30 de mayo de 1972b). En este párrafo se retrata a la cultura de los nativos desde lo exótico. Así pues, se la muestra como retrasada ya que se hace referencia a los modos de vida de los indígenas, específicamente a su forma de vestir, la cual nada tiene que ver con lo propuesto por las costumbres de la cultura occidental, con las cuales se identifican el resto de la población ecuatorian desde la asunción de la blanquitud como su rasgo identitario (Echeverría, 2010).

En los 80 el conflicto con Perú evidencia la desconexión que existe entre la Amazonía y el resto del país, así se publican noticias como: «Hay que lograr integración de nuestra región oriental». En esta se habla de la importancia de integrar a la región como un método preventivo de futuros ataques a la zona fronteriza. De este modo, se señala:
Uno de los beneficios que pueden derivar de la reciente agresión peruana debe ser una programación del esfuerzo nacional para lograr la definitiva integración de la Región Amazónica a la existencia civilizada, expresó el vicepresidente de la Cámara Nacional de Representantes, Gil Barragán (El Comercio, 17 de febrero de 1981).

Con estas declaraciones se representa a la región como retrasada, pues literalmente se dice que la región debe ser integrada a la «existencia civilizada», lo cual quiere decir que se tiene la convicción de que en la región no existe cultura ni civilización. Este tipo de representaciones van en desmedro de la población nativa y su cultura.

Luego se hace alusión al imaginario que se tiene sobre la región amazónica al recoger más declaraciones de Barragán, quien afirma: «las provincias orientales son todavía un gigantesco espacio casi vacío que se conserva igual a como dejaron los primeros colonizadores. 'Ni siquiera existe un buen camino de penetración de Loja a Zamora', destacó» (El Comercio, 17 de febrero de 1981). Con esto se representa a la región como retrasada pues se dice de forma latente que no ha existido ningún «progreso» desde la época colonial. Estos parámetros de progreso versus retraso los marca la cultura occidental poniéndose a s misma como el ejemplo de lo que es progreso y desarrollo (Said, 2008; De Sousa Santos, 2010). Bajo estos cánones por supuesto que la región aparece como retrasada. Por otro lado, se invisibiliza a la población nativa y a su cultura pues se sugiere que la región ha estado despoblada lo cua no es cierto porque este territorio ha sido habitado históricamente por nacionalidades indígenas. Durante la década de los 90 aparecen noticias que representan negativamente a las tradiciones culturales de los pueblos amazónicos. Un ejemplo de esto es el reportaje: «Con lanzas desde todos los lados». El artículo recoge las declaraciones 
de la misionera Rachel Saint, quien habla de los Huaorani, que en esa época eran más conocidos como «Aucas». De este modo, Saint dice:

Los aucas vivían en un caos. Un hombre podía casarse con una mujer y su hija o con dos hermanas. Había la práctica del 'amor libre'. Un hombre tenía hijos en muchas partes. Cuando el niño crecía e iba a casarse con una chica, descubrían que eran hermanos. Si eso no es un caos usted no ha leído el Viejo Testamento (El Comercio, 21 de noviembre de 1993)

Con esta narración se critica desde los cánones occidentales a la cultura de la nacionalidad Huaorani ya que se afirma que «vivía en un caos». Las prácticas de la poligamia y el incesto son cuestionadas porque la cultura cristiana occidental las prohíbe, sin embargo, este tipo relaciones afectivas son muy comunes y normales en otras culturas, como las amazónicas. Sin embargo, esto no se advierte en la nota y, por lo tanto, el lector promedio del periódico que está familiarizado y que asume la cultura occidental como suya (Echeverría, 2010) tiende a formarse un imaginario negativo de las culturas de la Amazonía, pues como ya se dijo estas prácticas están proscritas desde el punto de vista occidental.

En la primera década de los 2000 las noticias continúan representado a las culturas amazónicas desde la otredad. Así, se publica la nota: «15 días para que los jóvenes de Sarayacu se gradúen de cazadores». Este pequeño artículo cuenta que los jóvenes adquirieron la destreza de cazar animaes. Así se señala: «15 días bastaron para que los jóvenes de Sarayacu se gradúen de cazadores» (El Comercio, 18 de febrero de 2007). Con esta información se hace referencia a la cultura de la comunidad Sarayaku, la cual es representada como retrasada porque según la breve noticia sus pobladores todavía viven de la caza, algo que ya no es común en la cultura occidental. Desde la perspectiva eurocéntrica este tipo de prácticas son rudimentarias, pues en la modernidad el hombre ya no depende directamente de la naturaleza para obtener fuentes de alimento, sino que, con técnicas como la domesticación de animales, es el propio ser humano quien aparentemente controla sus fuentes alimenticias. Tomando en cuenta esto, decir que existen comunidades que obtienen sus alimentos por medio de la cacería es representarlas como retrasadas.

Durante el último periodo estudiado, se oberva cómo evoluciona el tratamiento del tema de los servicios básicos en la región. En este sentido, aparece la nota: «El Pangui ve al cobre de Mirador como una salida a sus necesidades». El contenido del reportaje cuenta que la mayoría de los habiantes de la zona tiene puestas sus esperanzas en las regalías mineras para cubrir sus requerimientos básicos. Para iniciar se relata:

Las necesidades insatisfechas en El Pangui son básicas: mejorar los deficientes sistemas de alcantarilado y agua potable, dotar de mayores equipos e infraestructura al centro de salud, ampliar las posibilidades de estudio de los jóvenes y aumentar el ingreso per cápita mensual, que oscila entre USD 200 y 400 (El Comercio, 25 de marzo de 2012b).

Con esta descripción se representa a la zona como retrasada pues si bien se dice que cuenta con servicios, estos son descritos como deficientes. De esta manera, se afirma que en materia de anidad, educación, salud e incluso empleo, la población local todavía tiene muchas carencias. Si bien se dice que los poblados amazónicos ya cuentan con varios servicios, también se afirma que estos son deficitarios e insuficientes para cubrir las necesidades de quienes habitan la región. Este tipo de información lejos de ayudar que a a gente para que sus problemas sean resueltos, construye una imagen negativa de la región pues se termina diciendo que es una zona que no ga- rantiza a la población condiciones mínimas para vivir. Por lo tanto, la región es representada como retrasada desde la perspectiva occidental.

\section{Conclusiones}

Para finalizar hay que decir que el Análisis Crítico de Discurso aplicado a las 442 publicaciones de E Comercio permitió descubrir que la Amazonía si ha sido representada como el oriente ecuatoriano desde el discurso orientalista durante las últimas seis décadas. En este sentido, la población amazó nica ha sido mostrada como ignorante, inferior $y$ natural pues en las representaciones mediáticas se afirma que los indígenas carecen de escolaridad viven sumidos en la pobreza y no tienen acervo cultural ni agentividad social. En los primero periodos de estudio esto es más evidente pues explícitamente se utilizan términos peyorativos para referirse a ellos, por ejemplo a los indígenas de sur los llaman jíbaros y a los del norte de la región los denominan aucas. Mientras que en los últimos periodos analizados las representaciones son má bien implícitas, se muestra negativamente a la población originaria pero de forma latente, sin el uso de términos ofensivos. Ahora bien, hay que decir que esta forma de representar a la población indígena tiene su raíz en la necesidad de mostrarla como gente incapaz de aprovechar y administra los recursos naturales que sus suelos poseen. As pues, el medio justifica los planes de colonización de la región impulsados por sus gobiernos aliados hasta hace dos décadas.

En cuanto a la geografía se puede afirmar que El Comercio la representa como fértil y productiva pues en todos los periodos se resalta el potencia agrario de la región, desde los setenta se indica el potencial petrolero y a partir de los 2000 se empieza a hablar del potencial turístico de la zona. No obstante, las representaciones de tono negativo también son abordadas durante los sei periodos analizados. Así pues, de forma sistemática se construye la imagen de un «Oriente» peligroso y distante. En este sentido, se afirma que las condiciones geográficas y climáticas de la región la hacen propensa a sufrir desastres naturales. De igual manera, se dice que los poblados amazónicos son lejanos y que están desconectados del país; lo cual hace que la región sea percibida por el resto de ecuatorianos negativamente (Said, 2008), pues según El Comercio es una zona ajena.

Por último, la cultura de los pueblos amazónicos es representada por el diario como retrasada esto se hace en base a dos temas. El primero, la cobertura de servicios básicos que es un tópico recurrente durante todo el periodo de estudio. Sobre este tema se recalca que la Amazonía no cuenta con servicios básicos de energía, sanidad, educación, vialidad. Así pues, este tipo de representaciones que tal vez tenían la intención de denunciar las carencias de la región, terminaron por construi una imagen negativa de ella, mostrándola como una zona retrasada del progreso. Entonces, estos artículos lejos de ayudar a solucionar los problemas de la región, contribuyen a su empeoramiento porque decir que la región no presta las condiciones mínimas para vivir ha impedido a lo largo de la historia que profesionales de las diferentes ramas vayan a trabajar en estas poblaciones, lo cual ha privado a los amazónicos de servicios y derechos fundamentales como la salud.

La segunda tiene que ver con las representaciones que se hacen de las prácticas culturales de las nacionalidades indígenas de la región. En este sentido, se representan sus tradiciones como arcaicas y rudimentarias desde el punto de vista eurocéntrico. Así pues, se dice que sus formas de vestir o alimentarse nada tienen que ver con lo establecido por los cánones de la cultura occidental, patrones culturales con los que el resto de los ecuatorianos se sienten identificados, pues como 
se ha dicho la población mestiza tiene asumida la blanquitud como su rasgo identitario (Echeverría, 2010). Entonces, todo aquello que se salga de lo definido por la cultura occidental será percibido como retrasado

En definitiva, se puede afirmar que el diario El Comercio construyó a la Amazonía ecuatoriana desde la otredad. Así pues, se representa a la región como una zona donde habitan poblaciones extrañas y de cultura retrasada que de-

ben ser colonizadas para poder aprovechar sus riquezas naturales en «beneficio del país». Esta es la idea que los medios le han vendido al resto de ecuatorianos sobre el mal llamado «Oriente», porque hay que decir que esta expresión que han utilizado los medios para referirse a la región no tiene que ver solo con la posición geográfica que ocupa en el territorio nacional; sino con todo un discurso orientalista encaminado a construir a la Amazonía desde la otredad.

\section{Bibliografía}

Becker, Ingrid. (2013). «Juegos del lenguaje: hacia una aproximación al discurso colonial». En Alternativas epistemológicas: axiología, lenguaje y politica, (pp. 101-115). Buenos Aires: Prometeo Libros.

Cerbino, M. (2012). El lugar de la violencia. Perspectivas críticas sobre pandillerismo juvenil. Quito: Taurus.

Champagne, Patrick. (1999). «La visión mediática». En La miseria del mundo, (pp. 51-63). Buenos Aires: Fondo de cultura económica de Argentina

Charaudeau, P. (2003). El discurso de la información. La construcción del espejo social. Barcelona: Editorial Gedisa.

De Sousa Santos, B. (2010). Refundación del Estado en Amèrica Latina. Perspectivas desde una epistemología del Sur. Quito: Abya-Yala.

Echeverría, B. (2010). Modernidad y blanquitud. México: Ediciones Era.

Hall, S. (1997). El trabajo de la representación. En Representation: Cultural Representations and Signifying Practices (pp 13-74). Londres: Sage Publication

Hall, S. (2010). Sin Garantias: trayectorias y problemáticas en estudios culturales. Popayán: Envión Editores

Lippmann, W. 2003. La opinión pública. Madrid: Langre. Moscovici, S. (1979). El psicoanálisis, su imagen y su público. Buenos Aires: Editorial Huemul S. A

Pierre, F. (1999). Viaje de exploración al oriente ecuatoriano 1887-1888. Quito: Ediciones Abya - Yala

Raiter, A. (2002). «Representaciones sociales». En Representaciones sociales (pp. 9-30). Buenos Aires: Editorial Universitaria de Buenos Aires.

Said, E. (2008). Orientalismo. Madrid: Librerías Prodhuf, S. A. Van Dijk, T. (2005). «Política, ideología y discurso». Quorum Académico, 2 (2), 15-47.

Van Dijk, T. (2009). Discurso y poder Contribuciones a los estudios criticos del discurso. Barcelona: Gedis

Wodak, R. y Mever, M. (2003). Métodos de Análisis Crítico del Discurso Barcelona: Editorial Gedisa.

\section{Bibliografía consultada en períodicos}

Con lanzas desde todos los lados. (1993, 21 de noviembre). El Comercio, p. 6

Desbordamiento de ríos en región de Canelos acarreó tragedia a los habitantes. (1964, 30 de septiembre). El Comercio, p. 15

El Pangui ve al cobre de Mirador como una salida a sus necesidades. (2012b, 25 de marzo). El Comercio, p. 2.

Exposición amazónica del Ecuador se inauguró en San Antonio de Pichincha. (1972b, 30 de mayo). El Comercio, p. 7.

Hace 3 años señalose la obligación de construir oleoducto. (1972, 24 de junio). El Comercio, p. 13.

Hay que lograr integración de nuestra región oriental (1981, 17 de febrero). El Comercio, p. 3.

La Cordillera del Cóndor. (1981, 30 de enero). El Comercio,

La naturaleza seduce en Lumbaqui. (2012,04 de febrero). El Comercio, p. 10

Los pueblos no contactados siguen en riesgo. (2007, 02 de marzo). El Comercio, p. 21.

Padres e hijos estudian a distancia. (2012a, 25 de marzo). E Comercio, p. 8

Petróleo y deterioro ambiental. (1993, 20 de septiembre). E Comercio, p. 15

Proyecto del INC para la colonización del Valle de Río Upano está en marcha. (1964, 02 de junio). El Comercio, p. 1.

Región Amazónica: esperanza, dolor, promesa.... (1981, 0 de enero). El Comercio, p. 30-31.

Ruinas Arqueológicas del Oriente Ecuatoriano. (1964, 24 de junio). El Comercio, p. 5.

Sector central de El Puyo está sin servicio de luz eléctrica. (1964, 17 de julio). El Comercio, p 16

Texaco, enjuiciada. (1993, 05 de noviembre). El Comercio, p. 10

3 muertos al naufragar una canoa en río Coca. (1972a, 30 de mayo). El Comercio, p. 12.

4 escenarios para el mayor campo petrolero del país. (2007. 31 de marzo). El Comercio, p. 1

15 días para que los jóvenes de Sarayacu se gradúen de cazadores. (2007, 18 de febrero). El Comercio, p. 1.

25 años de la matanza de misioneros por los aucas. (1981

25 de enero). El Comercio, p. 